the result of similar biochemical lesions ? Though a rise in serum enzyme levels may in some instances help to define cases and carriers, here one is observing merely an end result. Incidentally, no reference to serum creatine kinase appears in the index though the value of this enzyme in diagnosis is discussed.

The inclusion of entities as dissimilar as, for example, the Duchenne type of dystrophy and myotonic dystrophy within the same general category of inherited disease is merely a taxonomic convenience, since the only common factor appears to be the involvement of muscle and this in distinctly different ways. Again, the associated features of these two diseases taken as representatives of the group are revealing. In myotonic dystrophy, testicular atrophy, frontal baldness, and cataract are well known, but the mental retardation in some boys with Duchenne dystrophy is less well known. As the authors indicate, the biochemical lesions responsible for these varied non-muscular manifestations of the dystrophies are likely to be as heterogeneous as are the clinical features and the modes of inheritance. One feels that major advances in our understanding of the dystrophies are imminent. They are certainly needed.

This volume of Progress in Medical Genetics provides a further addition to a useful series of authoritative reviews.

R. HARRIS

Annual Review of Genetics, Volume 1, 1967. Edited by H. L. Roman. Associate Editors Laurence M. Sandler and Gunther S. Stent. (Pp. vii +334 ; illustrated. $\$ 8.50$ in U.S.A., $\$ 9.00$ elsewhere.) Palo Alto, California: Annual Reviews Inc. 1967.

This is the first volume of a projected series of 'Annual Reviews of Genetics', from the same publishers as the similar 'Annual Reviews' which cover a variety of scientific disciplines from nuclear science to psychology. The editorial committee point out that, though reviews of various genetical subjects are not lacking, they are 'scattered in a variety of periodicals'; the stated object of the present volume is to bring together 'critical rather than comprehensive reviews' on topics of interest.

The book consists of 13 separate articles, of about 2030 pages each, covering a wide range of such topics as 'Human Genetics' (H. Eldon Sutton); 'Population Genetics' (R. C. Lewontin); 'Biochemical Aspects of Drosophila' (H. K. Mitchell); 'Structural Relationships between Gene and Protein' (Charles Yanofsky), etc. The choice of subject matter included in each review is of course a personal one, the limitation of space necessitating a rigid selection. Different contributors react to the challenge in different ways. Some, as exemplified by the first chapter on human genetics, provide staccato listings and short notes on a large number of recent developments, while others such as Sheldon Wolff's excellent discussion of radiation genetics take a particular controversy and devote most of the available space to a closely reasoned examination of the current evidence on the point in question.

For the most part, the level at which the subject matter is treated is such as to be comprehensible to a nonspecialist with a general genetical knowledge. A helpful point is the noting at the start of each chapter, of the date on which the literature survey was concluded. The production of the book is of a high standard, but the uniform appearance of over 300 pages of text is somewhat monotonous. Skimming rapidly through the chapters would be easier if the italicized subheadings were more prominently displayed, and a greater number of illustrations would be welcome.

There will be few geneticists who will not find something of use and interest in this book, but a small number will read it avidly from cover to cover. Perhaps the greatest value of a volume of this sort is that it provides easy access to areas of genetics with which one is not usually concerned. One result of the recent rapid expansion of genetical knowledge has been a deterioration of intradisciplinary communication; though this may be an inevitable development, anything which will tend to minimize it is surely of value.

Martin Bobrow

\section{Proceedings of the Third International Congress of}

Human Genetics. (The University of Chicago, Chicago, Illinois, U.S.A., September 5-10, 1966.) Edited by James F. Crow and James V. Neel. (Pp. xviii + 578; illustrated + tables. 138s.) Baltimore: The John Hopkins Press. U.K. DistributorsLondon: Oxford University Press. 1968.

This volume contains most of the papers read at plenary sessions and arranged symposia at the Third International Congress of Human Genetics held in Chicago in September 1966. It is inevitably somewhat of a mixed bag of opening statements, speculative papers on the past and future of man, reports of specific research enterprises, and reviews designed to establish the present status of knowledge of certain subjects. Inevitably also it is difficult to justify the printing of some addresses except that it would have been invidious to leave them out.

However, there are some excellent papers, some of the reviews form good sources of references, and there are a few reports of interesting new work. The volume can be recommended as introductory and stimulating reading for those becoming interested in human genetics.

The editing has been done carefully and effectively, and the printing and diagrams are of a high standard.

A. C. Stevenson

\section{Symposium on Autoimmunity and Genetics} Supplement to Clinical and Experimental Immunology, Vol. 2, December, 1967. Edited by W. W. Buchanan and W. J. Irvine. (Pp. 131; illustrated + tables. 30s.) Oxford: Blackwell Scientific Publications. 1967.

The first volume, published as a supplement to Clinical and Experimental Immunology, presents the proceedings of a symposium on auto-immunity and 